\title{
Organizational Impacts of Enhancing a BI-Supported Performance Measurement System on the Israeli Police
}

\author{
Marina Vugalter \\ Ben-Gurion University of the Negev, \\ Department of Industrial Engineering and Management. \\ POB 653, 8410501, Beer-Sheva, Israel \\ Email: vugalter@post.bgu.ac.il
}

\begin{abstract}
Performance Measurement Systems (PMS) have long captured the attention of organizational behavior and information systems (IS) research. The PMS in the study was implemented by public police forces, using advanced Business Intelligence (BI) technologies. The study examines the impact of enhancing that PMS, through analysis of the metric results over an 8-year time period that covered a transition between two major system versions. The analysis results indeed show a significant impact of transitioning to the new PMS in most (75\%) performance metrics. A noticeable impact of the transition is the temporary performance decline, followed by some improvement that can be attributed in part to the redefinition of some metrics. Further, the results confirmed the preliminary assumptions that the improvement in the measured performance is positively and significantly associated with humanresource allocation; however, with some mediation effects of the crime category and the organization unit.
\end{abstract}

\section{INTRODUCTION AND BACKGROUND}

Today, PMS are broadly adopted across all industries and business domains, and their implementation is often supported by Business Intelligence (BI) technologies [1], [2]. PMS implementation is driven by the notion that consistent and well-organized measurement, reflecting past behavior and current state of organizational units, can serve as an important tool for supporting decision-support and driving continuous performance improvement [3]. PMS may back these goals by providing solutions for gathering, analyzing, and distributing relevant information [4]. Much of the PMS research so far is non-empirical, and not supported by rigorous evidence [5]. Further, PMS studies mostly focus on forprofit businesses [6], but less on organizations that are not necessarily driven by profit goals, such as governmental agencies or community-based groups [7].

This study explores the impact of a PMS in a real-world setting, within a governmental agency - the Israeli Police Forces. The research scope is examining the transition between two PMS: the "MENAHEL" that was used between

This work was not supported by any organization

\author{
Adir Even \\ Ben-Gurion University of the Negev, \\ Department of Industrial Engineering and Management. \\ POB 653, 8410501, Beer-Sheva, Israel \\ Email: adireven@bgu.ac.il
}

2006 and 2010, and the "MIFNE" that replaced it in 2010. Both PMS were implemented with advanced Business Intelligence (BI) technologies and embedded a number of performance metrics that reflect the police strategy and activities. Beyond enhancement of BI technologies, a key difference between the systems was the re-design of the metrics structure. While the "MENAHEL" offered a large number of metrics (over 150), some with low relative weight, the "MIFNE" offered a reduced and more focused set that was developed based on the knowledge and insight that were gained during the operation of the "MENAHEL". The focus of "MIFNE" is not the quantity of measures, as the quality and essence. The newer system exposes police officers not only to performance measures in their own stations, but in other stations as well for the sake of comparison. Further, the newer performance measurement system serves not only police stations, but rather all organizational police units. One new main module that is part of "MIFNE" is "internal services"- as part of the comprehension of the importance of police officer's and his family's social satisfaction. Moreover, "MIFNE" is targeting every organizational unit specifically, compared to "MENAHEL" that defined a uniform target for all units. The new PMS enables to drilldown and investigation from high-level information to more detailed. It enables identification of exceptional trends or events that required an attention. According to research and statistics unit of the police, "MIFNE" brought a significant change in perception as part of a 3-years change program named "MIFNE" that has been started in 2011. Main guideline of this program is that public trust of the police, has an important and critical rule. In order to focus all organizational units on achieving "MIFNE" strategy, "MIFNE" program is based on a unique PMS named "MIFNE".

A question that motivates this study is whether or not the transition to a new PMS promoted the desired improvement in police-units performance. Was the influence positive, or rather negative in some cases? Is the influence moderated by certain characteristics of the organizational unit? This study suggests that these questions may have important implications for performance measurement in the Israeli police as for the adoption of PMS in other organizations. 


\section{MODEL DEVELOPMENT}

The transition between the two PMS systems raised questions that this study aims to explore: did the transition indeed gained the desired effect on performance measurement? What factors may possibly affect the actual contribution of replacing a PMS? One could expect that the actual contribution will be affected by factors such as the size of police station, socio-economic characteristics of its region, or the activity or crime category that the performance metrics reflect. These questions are reflected in the model that underlies this study (Figure 1), which is presented next.

The model observes the following constructs:

Performance (P): The dependent variable observed is the organizational performance as reflected in the values of the PMS metrics. Positive and/or negative trends in metric values reflect the influence transitioning to a new PMS and possibly other factors.

PMS Replacement (R): Transition to a new PMS is expected to have a significant impact on performance. Accordingly, the first set of hypotheses reflects possible manifestations of that impact:

- H1a: PMS Replacement will significantly affect performance.

- H1b: PMS Replacement significantly improves performance over time.

- H1c: PMS Replacement may result in a temporary performance decline during the transition period

Resources Allocation (A): An alternative, or possibly complementary, explanation to the effect of PMS replacement on performance is the allocation of resources. Performance could have been enhanced not only by PMS replacement, but also by extending human-resource allocation, where the effect is expected to be positive:

- H2: Increasing human resource allocation will improve the measured performance

Socio-Economic Ranking (S): The common assumption in literature is that socio-economic ranking may influence on the dependent variable in some researches as in politics and government [8] and entrepreneurship [9]. Certain demographic characteristics, such as the socio-economic ranking of the region in which the police station acts, are expected to moderate the effect of PMS replacement on the measured performance. We therefore assume that:

- H3a: Stations that act in regions with different socioeconomic ranking will show difference in the influence of replacing PMS on the performance

Performance Category (PC): PMS commonly arrange the performance metrics in clusters. For example, in PMS that are based on the Balanced Score-Card (BSC) methodology [10], the measurements are categorized under four key clusters. Such categorization could be detected in the police PMS as well, and the model assumes that this categorization will have some effect:

- $\boldsymbol{H} 3 \boldsymbol{b}$ : Different performance categories will show different influence of PMS replacement on performance.

Crime Category $(\boldsymbol{C C})$ : The police typically characterize different types of crime along different categories. The model assumes that different crimes category will show different effect of replacing PMS on performance:

- H3c: Different crime categories will influence of PMS replacement on performance differently.

Police Station (PS): There is a different effect on measures among different police stations so stations differ from each other in PMS enhancing. Considering common qualities of police stations assist to divide them to clusters. Each Cluster is differ from other in internal and external characters. This examination helps assessing whether or not performance measures are effected from internal (HR allocation, socioeconomic ranking) and external (crime records) police stations characteristics. The assumption is that the influence of replacement PMS on performance is expected to be different between different police stations. The model assumes that different police stations will show different effect of replacing PMS on performance:

- H3d: Influence of PMS replacement on performance is different between different police stations.

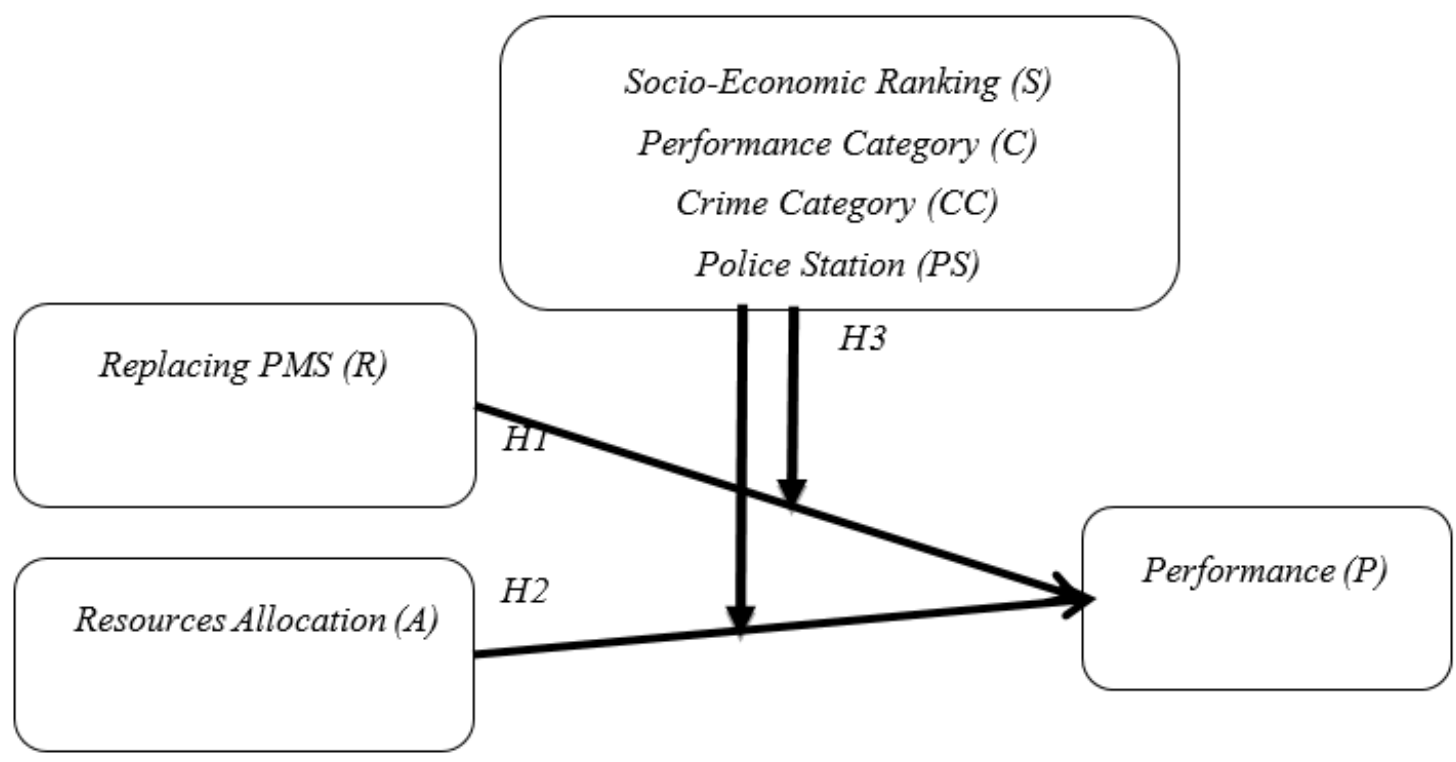




\section{DATA PREPARATION AND PRELIMINARY ANALYSIS}

The study was based on performance measurements that were retrieved from the police database, with some additional pieces of data that were retrieved from other sources. The measurements covered an 8-year period (January 2006 to December 2013), 146 organizational units (districts, regions, special units, etc.), and 33 performance metrics - 8 annual measures, per metric and per unit. The 33 metrics can be classified to 3 main categories: a) crime records, b) charges, and c) arrests. Each category includes 11 crimes that could be divided to exposure offenses versus the rest. Exposure offenses are crimes with no previous complaint or report; hence, exposed only by initiated activity. Exposure-based crimes are considered to be more challenging to handle than the others; hence, get extended attention by the police. One of main goals the police has put as a focus in front of her is increasing the probability of the criminal to be caught in exposure offences. 3 crimes out of 11 are considered as exposure offenses: weapons, illegal stay and drugs.

Another data resource that was used includes human resource allocation for each organizational unit per year. The datasets also contain socio-economic ranking, which was calculated as an average for all cities and regional councils' socio-economic ranking that under the responsibility of a certain police station. After removing records with missing or inconsistent values, and keeping only police stations that have full information of HR allocation and performance measures over 8-year period- 2006-2013, 60 valid stations remained, and were included in the analysis. The final dataset include one annual record per police station.

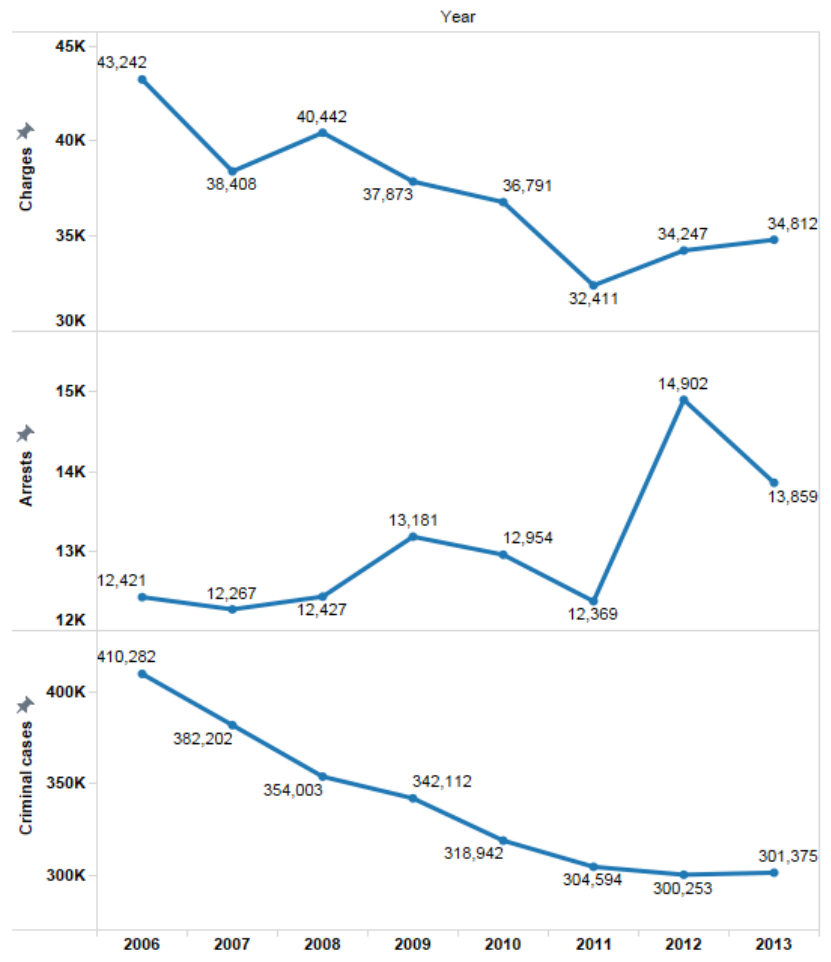

Fig. 2 Preliminary Performance Analysis
A preliminary analysis of 3 main categories: criminal cases, charges and arrests shows an improvement in metrics after the switch to the new system (2012); however, with some period of instability during the transition in 2011 (Figure 2). In addition, the ratio between arrests and crime records has a positive trend, and the ratio between arrests and charges is increasing as well over time. Among 15 performance measures out of $33(45.45 \%)$ there is an increase in performance following the switch and among the 33 measures, only for $2(6 \%)$ transition period (2011) is followed by improvement in performance, the rest of measures (94\%) are followed by decline in performance. Furthermore preliminary analysis shows a positive relationship between HR (number of police officers in a station) and performance measures: crime records, arrests and charges. A preliminary examination shows a strong correlation between crime records and arrests especially (Figure 3); however the correlation with charges measure seems to be weaker.

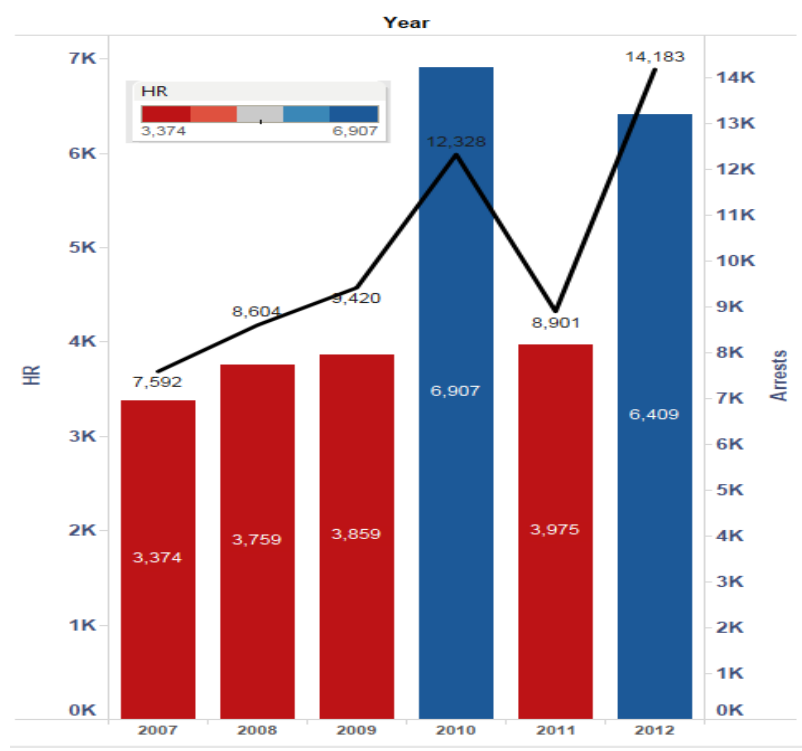

Fig.3 Arrests vs. Investment in Human Resources

\section{Evaluation Results}

This chapter reviews the analysis results of the model that is describes in chapter 3.

Testing Hypothesis H1: The Impact of Enhancing Performance Measurement Systems

The first hypothesis (H1) suggests that replacing the PMS will result in significant decline in performance during the transition period and also significant performance improvement following the replacement; the results support it partially. The datasets that were examined for this hypothesis is 3 year period between 2010 and 2012. In 2010 the former PMS was active. The transition to the new PMS system began in 2011. Then, the first version was active, followed by a year of the actual transition. By 2012, the transition was over and the new system became live in the organization.

The three derived hypotheses - H1a, H1b, and H1c - were tested by examining the rate of measures that had a signifi- 
cant effect $(\mathrm{P}-$ Value $<0.05)$ (Table 1). The H1a assumption that measures show significant change over time is largely supported, as for 25 out of 33 measures (75.7\%). The H1b assumption that measures will significantly improve following replacement wasn't supported- 24 out of 33 measures have no significant improvement $(72.7 \%)$. However most of the measures that were improved significantly are included in the arrests category. The H1c assumption that measures will significantly decrease during transition is also not fully supported. 31 measures among 33 had a decline in performance during the transition period (93\%), however, 10 only $(30 \%)$ had a statistical significant decrease.

TABLE 1 .

CHANGE IN PERFORMANCE MEASURES (H1)

\begin{tabular}{|l|c|c|}
\hline Hypothesis & Significant measures & Ratio \\
\hline H1a & 25 & $75.75 \%$ \\
\hline H1b & 9 & $27.27 \%$ \\
\hline H1c & 10 & $30 \%$ \\
\hline
\end{tabular}

Testing Hypothesis H2: The improvement in performance will be positively affected by human-resource allocation

$\mathrm{H} 2$ suggests that performance will be improved with higher human-resource allocation. The results support this assumption significantly. A preliminary analysis shows consistently-high correlation between HR allocation and performance improvement in three key metrics (Tables 2).

TABLE 2.

CORRELATION BETWEEN HR ALLOCATION AND PERFORMANCE (H2)

\begin{tabular}{|l|l|l|l|}
\hline Crime Metric & $\begin{array}{l}\text { Correlation } \\
\text { with Crime } \\
\text { Records } \\
\text { Performance }\end{array}$ & $\begin{array}{l}\text { Correlation } \\
\text { with Charge } \\
\text { Performance }\end{array}$ & $\begin{array}{l}\text { Correlation } \\
\text { with Arrests } \\
\text { Performance }\end{array}$ \\
\hline Regular violence & $83.58 \%$ & $57.98 \%$ & $61.22 \%$ \\
\hline Aggravated violence & $73.7 \%$ & $62.1 \%$ & $61.70 \%$ \\
\hline Total violence & $83.61 \%$ & $59.89 \%$ & $60.86 \%$ \\
\hline Property & $63.81 \%$ & $51.86 \%$ & $53.86 \%$ \\
\hline Sex & $54.67 \%$ & $43.60 \%$ & $39.73 \%$ \\
\hline Regular attack & $78.74 \%$ & $54.45 \%$ & $56.56 \%$ \\
\hline Aggravated attack & $69.53 \%$ & $61.20 \%$ & $50.67 \%$ \\
\hline Weapons & $1 \%$ & $22.1 \%$ & $0 \%$ \\
\hline Illegal stay & $11.2 \%$ & $0 \%$ & $21.0 \%$ \\
\hline Drugs & $48.52 \%$ & $57.2 \%$ & $30.30 \%$ \\
\hline & & \multicolumn{2}{|l}{} \\
\hline
\end{tabular}

A more detailed analysis shows that the extent of improvement varies between performance types. For some measures (e.g., violence, aggravated attack, regular attack, etc.), the correlation is significant $(\mathrm{P}-\mathrm{Value}<0.05)$, while for others "exposure offenses" (e.g., illegal stay, weapons, drugs trade) it is less significant (P-Value $>0.05$ ). The most significant difference is between exposure offenses and the others. As seen in table 2, among the 30 indicators that demonstrated in 3 categories (a table is presented for each category), 7 (70\% of all crime measures) have a significant correlation with HR allocation in all categories. All 3 exposure measures (30\% of all crime measures) have a low and not significant correlation.

Testing Hypothesis H3a: Station will show difference in the influence of replacing PMS, based on the socio-economic of the region under their control.

Hypothesis $\mathrm{H} 3 \mathrm{a}$, suggesting that the impact of replacing the PMS on performance is moderated by the socio-economic ranking, is supported in part. A repeated-measures ANOVA test shows influence of replacing the PMS on performance measures for the 3 key measures (H1a). The test confirmed the assumption H1a with high significance $(\mathrm{P}-$ Value $=\sim 0)$. However significant influence with respect to the interaction with Socio-Economic Ranking (H3a) could be found among 17 measures out of $33(\sim 50 \%)$. In crime records category, high significance $(\mathrm{P}-$ Value $=\sim 0)$ interaction was found in 7 out of 10 crimes categories $(\sim 70 \%)$, however for arrests category only among 3 crimes out of $10(30 \%)$ the interaction is significant and for charges category among 5 out of 10 can be seen a high significant interaction $(50 \%)$. This interaction is found as significant in all categories for crimes like violence and attack more than other crimes. The main conclusion that derived is that different stations will show difference in the influence of replacing PMS, based on the socioeconomic characteristics of the region under their control and crime category.

TABLE 3.

RATIOS BETWEEN SIGNIFICANT PERFORMANCE MEASURES (H3B)

\begin{tabular}{|l|l|l|l|}
\hline \multicolumn{1}{|c|}{ Impact } & \multicolumn{1}{|c|}{ Category } & $\begin{array}{c}\text { Significant } \\
\text { Metrics }\end{array}$ & \multicolumn{1}{c|}{ Ratio } \\
\hline Total & Crime records & 7 & $70 \%$ \\
Change & Charges & 7 & $70 \%$ \\
& Arrests & 9 & $90 \%$ \\
\hline Increase & Crime records & 1 & $10 \%$ \\
& Charges & 1 & $10 \%$ \\
& Arrests & 7 & $70 \%$ \\
\hline Decrease & Crime records & 5 & $50 \%$ \\
& Charges & 4 & $40 \%$ \\
& Arrests & 1 & $10 \%$ \\
\hline
\end{tabular}

Testing Hypothesis H3b: The influence of PMS replacement on performance is will differ between metric categories

The third hypothesis ( $\mathrm{H} 3 \mathrm{~b})$, is suggesting that the impact of enhancing PMS on performance will be moderated by performance category. This sub-hypothesis is derive from $\mathrm{H} 1$, which assumes that replacing PMS has an impact on the performance. This hypothesis (H3b) suggests that replacing the PMS will result in significant decline in performance 
during transition period and also significant performance improvement following the replacement is dependent on performance category; Results of examination the impact on performance by considering 3 performance categories are presented in Table 3.

For most crimes in all 3 categories some significant change in performance measures could be detected (P-Value < 0.05). For arrests, the ratio of crimes that had a significant change, is the highest- $90 \%$, and for the other 2 categories the ratio is $70 \%$ which is pretty high as well. Regarding the increase in performance following the replacement, for both crime records and charges categories, the ratio is $10 \%$, however for arrests category- ratio of crimes with significant improvement is $70 \%$. It seems that there was no significant decrease in performance in transition period for none of the category in all crimes. For crime records category, 50\% of crimes had a significant decline in performance, for charges category $40 \%$ and for arrests only $10 \%$ from crimes.

TABLE 4.

P-VALUE Results (H3C)

\begin{tabular}{|l|c|c|c|}
\hline Category & Arrests & Charges & Crime Records \\
\hline Regular violence & 0.00 & 0.00 & 0.00 \\
\hline Aggravated violence & 0.01 & 0.08 & 0.02 \\
\hline Total violence & 0.00 & 0.00 & 0.00 \\
\hline Property & 0.02 & 0.316 & 0.05 \\
\hline Sex & 0.588 & 0.55 & 0.115 \\
\hline Regular attack & 0.05 & 0.01 & 0.00 \\
\hline Aggravated attack & 0.11 & 0.14 & 0.187 \\
\hline$*$ Weapons & 0.06 & 0.06 & 0.01 \\
\hline$*$ Illegal stay & 0.00 & 0.00 & 0.638 \\
\hline$*$ Drugs & 0.00 & 0.14 & 0.00 \\
\hline total & 0.00 & 0.00 & 0.00 \\
\hline
\end{tabular}

Testing Hypothesis H3c: The influence of PMS replacement on performance will be differ between crimes categories.

The third hypothesis $(\mathrm{H} 3 \mathrm{c})$, is suggesting that the impact of enhancing PMS on performance will be moderated by the crime category. This sub-hypothesis is derive from H1 as well. This hypothesis $(\mathrm{H} 3 \mathrm{c})$ suggests that replacing the PMS will result in significant decline in performance during transition period and also significant performance improvement following the replacement, dependent on crime category; examination results of the impact on performance by considering 11 crime categories show that for sex and aggravated attack crimes there is no significant change in performance in none of the categories (Table 4). Also, for illegal stay crime records category and for drugs charges, the change in performance is no significant; however for rest of crimes $(80 \%)$ the change is significant in all categories for 6 crimes and for the rest 2 , is significant in 2 categories out of 3 .
None of the above crimes has a significant improvement or a significant decline in all categories (Table 4).

Testing Hypothesis H3d: Influence of PMS replacement on performance is different between different police stations.

The third hypothesis (H3d), is suggesting that the impact of enhancing PMS on performance will be moderated by the police station. This sub-hypothesis is suggesting that the influence of replacing PMS is differ from one station to other. In order to test this assumption, all 57 police stations were divided to 6 clusters. One cluster included all "nonjewish" police stations and the rest of 45 police stations were classified to 5 clusters by k- medoids algorithm. This classification shows a partial support to the assumption; for sex crimes and illegal stay- charges and arrests categories there is a significant interaction with clustering (Table 5). Also, for aggravated attack crimes -charges, the interaction is significant. Cluster analysis was made according to measures: HR allocation, socio-economic ranking, and criminal charges in crimes: regular violence, aggravated violence, aggravated attack and property. After a cluster analysis was done, results of repeated measures ANOVA show that the only crime category with significant interaction is criminal charges. However this result is obvious since the cluster analysis is based on criminal charges measures, as mentioned above. Moreover it is clear (Table 5) that for some measures as sex and illegal stay in arrests and charges categories and also in aggravated attack charges, the influence on performance measures is dependent on the cluster attribute.

TABLE 5 .

$\mathrm{P}$ VALUE RESULTS- $\mathrm{K}=5(\mathrm{H} 3 \mathrm{D})$

\begin{tabular}{|l|l|l|l|}
\hline Crime Metric & $\begin{array}{l}\text { Crime } \\
\text { Records }\end{array}$ & Charges & Arrests \\
\hline Regular violence & 0.00 & 0.14 & 0.76 \\
\hline Aggravated violence & 0.00 & 0.14 & 0.98 \\
\hline Total violence & 0.00 & 0.09 & 0.90 \\
\hline Property & 0.00 & 0.09 & 0.12 \\
\hline Sex & 0.43 & 0.00 & 0.00 \\
\hline Regular attack & 0.09 & 0.09 & 0.47 \\
\hline Aggravated attack & 0.00 & 0.03 & 0.71 \\
\hline Weapons & 0.69 & 0.985 & 0.92 \\
\hline Illegal stay & 0.13 & 0.02 & 0.02 \\
\hline Drugs & 0.08 & 0.498 & 0.11 \\
\hline
\end{tabular}

Following repeated measures ANOVA, determining directionality of measures is defined as next step. Tukey HSD test was done in order to determine what police stations clusters achieved better performance in each year and who improved over time. Results of Tukey HSD test for illegal stay arrests measure show that cluster 2 is in total better than clusters 3 and 4 ; police stations that relate to cluster 2 perform better than those that relate to clusters 3 or 4 . In addition, the per- 
formance is higher in 2012 than in 2010. Results of Tukey HSD test for illegal stay charges measure show that cluster 1 is in total better than clusters 4 and 5 , so the number of illegal stay charges is higher in stations from cluster 1 than clusters 4 or 5 . For conclude illegal stay crimes, one can say that there is significant difference between police stations that relate to different clusters in performance. Regarding sex arrests measure, cluster 1 is seen to be better than 4 and 5 in 2010-2012. Moreover, cluster 2 is better than 3,4 and 5 and 3 is better than 4 and 5. Police stations that related to cluster 3 improved in sex arrests measure significantly over time. Regarding sex charges measure, the results show that clusters 1 and 2 have higher performance than 3, 4 and 5. Moreover cluster 3 is better than 5 and also than 4 in 2011-2012. In sex charges, as in sex arrests, cluster 3 has improved in 2012. These results support the assumption that influence of PMS replacement on performance is different between different police stations however it's significant with dependent on crime category.

TABLE 6 .

SUMMARY OF RESULTS

\begin{tabular}{|c|c|c|c|}
\hline & & Hypothesis & Supported? \\
\hline H1 & H1a & $\begin{array}{l}\text { PMS Replacement will signifi- } \\
\text { cantly affect } \\
\text { performance }\end{array}$ & Strongly \\
\hline & $\mathrm{H} 1 \mathrm{~b}$ & $\begin{array}{l}\text { PMS Replacement significantly } \\
\text { improves } \\
\text { performance over time. }\end{array}$ & Partially \\
\hline & $\mathrm{H} 1 \mathrm{c}$ & $\begin{array}{l}\text { PMS Replacement may result in } \\
\text { a temporary } \\
\text { performance decline during the } \\
\text { transition period }\end{array}$ & Partially \\
\hline $\mathrm{H} 2$ & & $\begin{array}{l}\text { Increasing human resource } \\
\text { allocation will improve the } \\
\text { measured performance }\end{array}$ & Partially \\
\hline $\mathrm{H} 3$ & H3a & $\begin{array}{l}\text { Stations that act in regions with } \\
\text { different socio-economic rank- } \\
\text { ing will show difference in the } \\
\text { influence of replacing PMS on } \\
\text { the performance }\end{array}$ & Strongly \\
\hline & $\mathrm{H} 3 \mathrm{~b}$ & $\begin{array}{l}\text { Different performance catego- } \\
\text { ries will show different influ- } \\
\text { ence of PMS replacement on } \\
\text { performance. }\end{array}$ & Strongly \\
\hline & H3c & $\begin{array}{l}\text { Different crime categories will } \\
\text { influence of PMS replacement } \\
\text { on performance differently. }\end{array}$ & Partially \\
\hline & H3d & $\begin{array}{l}\text { Influence of PMS replacement } \\
\text { on performance is different } \\
\text { between different police sta- } \\
\text { tions. }\end{array}$ & Partially \\
\hline
\end{tabular}

\section{V.DISCUSSION}

This paper had discussed the implementation and enhancing of a PMS in the Israeli public sector organization.

The literature and case data presented clearly shows first, the importance of updating and enhancing performance meas- urement systems in organizations so that they change over time, and second the factors that affect the performance measures as a result of enhancing process. There is not a significant evidence in the literature to enhancing PMS process in organizations, and in particular not in the public sector. This paper discusses many of these issues in the context of case study data in Israeli police relating to performance measurement systems evolution. A considerable amount has been written about design and implementation of performance measurement systems in organizations. Moreover one can find many researches about performance measures methodologies, success and failure factors and PMS development over time; however, there is a little discussion in the literature of what are the influences of enhancing PMS, and in the public sector even less. Israeli police data show clearly that enhancing PMS may have a strong impact on performance- some decline during transition period and improvement after it.

It is also clear that for performance measurement systems to enhance effectively there are factors that an organization must consider as internal characteristics of organizational units and measures categories. Reviewing these factors is an important stage in management enhancing PMS process in organizations. This research provides a view of the factors that may influence a process of enhancing a PMS and the impact of that.

\section{CONCLUSIONS}

This research examined the impact of enhancing PMS and factors that are possibly involved in that impact. The study shows that, generally, there is a significant change in performance in most of crimes' categories following enhancing PMS. The only crimes' categories that weren't affected from PMS enhancing are sex, aggravated violence, drugs trade charges and illegal stay records. The study shows that the improvement in performance following the change is mostly expressed in crimes from arrests category (an output measure): violence, attack, and illegal stay. Furthermore, for most of crime categories a decrease in performance during transition period was seen, however it's statistical significant only for $30 \%$ of measures. For violence and aggravated attack crimes there is a significant decrease in performance for arrests and charges, for drugs trade there is a significant decrease in crime records and arrests. In addition, it confirmed that performance will be improved with higher humanresource allocation in most crimes categories, except from exposure crimes; main conclusion for the police is that no matter how resource allocation is high, the impact on performance wasn't significant. We can conclude that without any consideration in size of human-resource in a police station, its performance in dealing with crimes like illegal stay, drugs trade and weapons remains the same. Police officers can learn from this study that

The quantity of the police force staff in a police station will not dramatically improve the quality of those measures, so the focus should be on the quality of HR and less the quanti- 
ty. Moreover, as suggested previously, the socio-economic ranking is shown to have a strong moderating effect on performance in crime records category, however for output measures as charges and arrests, it seems that changes in performance are not affected by socio-economic ranking.

The baseline assumption that a PMS system and, in particular, a BI-supported one has an influence on organizational change and improvement in performance has been confirmed. However, it's forbidden to neglect the negative incline in performance during the transition period that preceded the improvement.

\section{FutURE RESEARCH}

The literature claims that there is a need to a right management of performance measurement systems in both public and non-public sectors. Many researches are focusing on developing methodologies and reviewing the literature on PMS, however little empirical research has been carried out to assess their influence on performance measures, especially in the public sector. In order to better understand performance measurement in general and in the public sector in particular, this study can be extended in a few possible directions.

Some limitations are ought to be further addresses and explored since the study explores only a limited number of moderator variables that can influence the effect of replacing a PMS. Studies focusing on the following research questions would be of interest.

- Are the moderate variables that were analysed are the only main ones that can influence performance or other variables need to be considered?

- Is enhancing PMS improves performance over long period? How performance is influenced in the long term?
- Are other public organizations show same behaviour as the Israeli police? Is the influence of enhancing PMS is specific to this case study or common in other organizations as well?

- Is the influence on performance measures is the same on other measures that weren't included in this research but are part of the PMS?

To answer most of these research questions, additional academic and empirical research are required.

\section{REFERENCES}

[1] M. Bourne, 'Performance Management:learning from the past and projecting the future.' Measuring Business Excellence, 2008, Vol. 12, pp. 67-72. 10.1108/01443570010330739

[2] N. Yadav, M. Sagar 'Performance Measurement and Management Frameworks- Research trends to the last two decades.' Business Process Management Journal, Vol. 19, No.6, 2013, PP.947-970. 10.1108/BPMJ-01-2013-0003

[3] V. Vuksic, M. Bach, A. Popvic, Supporting PM with business performance and Business Intelligence: A case analysis of integration and orchestration. International Journal Of Information Management, Vol. 33, 2013, PP. 613-619. 10.1016/j.ijinfomgt.2013.03.008

[4] U. Bititci, P. Garengo, V. Dorfler, Performance measurement: Challenges for tomorrow.' International Journal of Management Reviews, 2012, PP. 327-305. 10.1111/j.1468-2370.2011.00318.x

[5] P. Micheli, M. Kennerley .'Performance measurement frameworks in public and non-profit sectors. Production Planning \& Control, 2005, 16(2)134-125 . 10.1080/09537280512331333039

[6] H. K .Rantanen, 'Performance measurement systems in the Finnish public sector,' International Journal of Public Sector Management, 2007.20(5). 10.1108/09513550710772521

[7] T. Boland, A. Fowler, 'A System Prespective of Performance Management in Public Sector Organizations'. The International Journal of Public Sector Management, Vol 13, No.5,2000, PP. 417446. 10.1108/09513550010350832

[8] A. Lijphart 'Corporatism and consensus democracy in eighteen countries: Conceptual and empirical linkages' British Journal of political science, 1991,246- 235 . 10.1017/S0007123400006128

[9] B. Batjargal 'Social capital and entrepreneurial performance in Russia: A longitudinal study.' Organization Studies 2003, 535-556. 10.1177/0170840603024004002

[10] R. S. Kaplan, D. P. Norton.'The balanced Scorecard-measures that drive performance.' Harvard Busisness Review, 1992, 71-79. 10. 2308/acch.2001.15.2.147 